\title{
The Legal Framework for Waste Management in Cameroon by International Environmental Law
}

\author{
Christian Daniel Beyeme \\ Department of Public Law, Faculty of Legal and Political Sciences, University of Douala, Douala, Cameroon
}

Email address:

beyeme_christian@yahoo.fr

\section{To cite this article:}

Christian Daniel Beyeme. The Legal Framework for Waste Management in Cameroon by International Environmental Law. International Journal of Law and Society. Vol. 4, No. 1, 2021, pp. 39-46. doi: 10.11648/j.ijls.20210401.15

Received: February 3, 2021; Accepted: February 18, 2021; Published: March 17, 2021

\begin{abstract}
The rules of international law find their authority in the provisions of Article $38\left(1^{\circ}\right)$ of the Statutes of the International Court of Justice, in four sources, namely: treaties, international custom, general principles of law, and secondary sources (court decisions, tribunals and doctrine). However, beyond these sources of "hard law", which impose binding obligations, there are also "soft law" rules whose obligations are not binding. However, it should be noted that new customary rules appear quite quickly, as does the speed with which global environmental issues take hold of the political calendar, tending to highlight the evolution of legal norms and to relegate customary law to the background, after conventions or treaties. Although some fundamental principles, such as the equitable use of resources can be attributed to decisions based on customary law, treaties are undoubtedly the main basis used by the international community to regulate activities threatening the environment. In this perspective, the legal framework for waste management in Cameroon by international environmental law is palpable through the ratification of treaties, international agreements because Cameroon is a signatory of conventions, codes, protocols, and international agreements which reinforce the existing legal instruments at the national level and especially which lend credibility to the environmental protection policy in general, and the efficient and environmentally sound management of waste in particular, with international partners.
\end{abstract}

Keywords: Waste, Environment, Convention, Treaty, International Law

\section{Introduction}

"The States of French-speaking Black Africa are parties, in their vast majority, to the main international instruments protecting human rights, whether universal or regional," [1] notes Professor René DEGNI-SEGUI. This academic observation is flattering for those States which, through this movement, are part of logic of protection of fundamental rights. However, being party to a human rights convention is not enough for it to create a formal obligation for the state. The procedures for signing and ratifying the said instruments must be respected as a prerequisite [2].

The internationalization of human rights has not spared the Cameroonian constituent, who has made it a point of honor to integrate these instruments into the national legal order. One could however wonder whether it was the place of these international texts in the legal order concerned. Before the constitutional reform of 1996, the constitutional text of 1960 devoted two provisions to treaties and international agreements, Articles 39 and 40.

Article 40 took up the wording of Article 55 of the French Constitution of 1958 which provided that: "treaties and agreements duly ratified or approved have, from their publication, an authority superior to that of laws, subject to each agreement or treaty, of its application by the other party". The clearly monist option was thus affirmed in Cameroonian law, with the primacy of international law over national law [3].

Substantially, the objective of this article entitled: "the legal framework for waste management in Cameroon by international environmental law", is to conduct a careful analysis of the hierarchy of standards. Which is ensured by certain modalities guaranteeing the principle of parallelism of forms and laws? By highlighting Cameroon's adherence to international principles of rigorous and environmentally sound management of waste and the international, regional and community conventions that have been ratified by Cameroon. 


\section{Cameroon's Adherence to International Principles of Waste Management}

To better understand Cameroon's adherence to international principles of rigorous and environmentally sound management of waste, it is important to dwell on the notion of the "principle", which Professor Maurice KAMTO considers to be polysemous in legal vocabulary, because it is used too lax in environmental law to the point of appearing there as a conceptual nebula.

For the Professor, the concept of principle is used interchangeably to designate a finding of evidence, the conclusion of an analysis, a non-legal standard or a binding legal rule. Thus, under the title of "guiding principles", we can evoke the Dublin declaration of January 1992 on water with its four principles of very different nature and scope and the Rio declaration with its twenty-seven (27) in the same way.

These two declarations have a legal claim whereas their statements are not all worded in normative terms. Although it should be mentioned that some are simple observations while others have a normative character that manifests itself through the use of the verb "must", imperative or prescriptive verb. In this case, it should be noted according to the expression of Professor KAMTO, that they are endowed with either an absence of legal rigor or an amalgamation [4].

However, in law, this term is more than a simple connotative statement. It signifies either a general norm of a non-legal character from which legal norms can be deduced, or a legal rule established by a text in fairly generous terms intended to inspire various applications and impose itself with a higher authority. In this case, the term refers to "positive principle of law", that is to say to a standard explicitly formulated in a text of positive law.

For Professor KAMTO, the principles are conceptual tools of interest and utility in the science of law. They are a definition and a normative crystallization of the fundamental values of the company; they indicate the fundamental objectives or the doctrine of the State and of society in a given matter: they are programming standards, the content of which the legislator or the judge will be responsible for specifying.

Even if, following Professor KAMTO, some authors oppose principles to legal rules. This opposition gave rise to an important debate in general theory of law to resolve the problem of its anchoring of this notion to the rule of law. This is the question of whether a principle of waste management is a legal rule. Is strongly shared as long as it is true that the dominant doctrinal tendency is that which believes that principles constitute rules of a new kind. For this purpose, we will retain the analyzes of Ronald DWORKINwho mobilized the principles to attack certain theories, developed in particular by Herbert Hart and Joseph RAZ [5], described as a positivist [6].

Clearly, for the first author, the principle is a legal proposition which is not necessarily written and which gives general orientations, directives which positive law must confront. While Herbert Hart and Joseph RAZ, in opposing many critiques to this thesis, pointed out that competing legal rules are likely to apply to a single situation and that conflicts can therefore arise between rules of positive law. These two authors believe that if the principles can be characterized by a certain weight, the same applies to legal rules, since some of them, for example, those which are of public order, are likely to have more weight than other.

As such, Joseph RAZ deduces that it would be preferable, in order to identify the principles, to resort to the degree of abstraction of the standard. He observes that the principle calls for indeterminate actions while the rules of positive law determine specific acts. The distinction would therefore be based on a difference of degree more than nature.

Thus, whatever the legal value of the principle in international environmental law, it must have a normative character to better regulate waste management. It is in this sense that Cameroon has adhered to these principles. This adhesion will allow us to distinguish the cardinal principle which is the principle of environmentally sound management of waste (1.1) and its derived principles (1.2) and the Operational principles arising from the Basel and Bamako conventions (1.3).

\subsection{The Cardinal Principle: The Principle of Environmentally Sound Management of Waste}

Environmentally sound management is undoubtedly the flagship rule guiding waste management, clearly enshrined in international instruments and included in the framework law, although it should be mentioned that it does not apply only to waste. Environmentally sound management calls for the implementation of a management method and therefore techniques and practices for waste treatment that ensure maximum respect and protection of the environment. It is this importance given to the objective of ecological rationality that led Aimé DOUNIAN to speak of a "cardinal principle of environmentally sound waste management" [7] that he derives from the use of other principles. It gives the environmentally sound management of waste the status and value of a legal principle of international environmental law, without it having been expressed as such by the international instruments which support it.

However, for the Cameroonian legislator, this principle aims to take all practical measures to ensure that waste is managed in a way that guarantees the protection of human health and the environment, against the harmful effects that may have this waste. It should be mentioned that the provisions of this principle are in conformity with that of the Bamako Convention which provides that: "States must take the necessary measures to ensure that waste management is compatible with the protection of human health and of the environment regardless of where the waste is disposed of" [8]. 


\subsection{Principles Derived from the Cardinal Principle and Complementary Principles}

Article 9 of the framework law [9], provides that the environmentally sound management of the environment is inspired by the laws, regulations in force, derived principles and complementary principles. The principle of precaution, prevention, participation, polluter paysresponsibility, etc. will be discussed in turn.

The precautionary principle which is considered to be one of the most important of the Rio Declaration on Environment and Development.

In Cameroon, this precautionary principle is a principle according to which: "the absence of certainty, taking into account the scientific and technical knowledge of the moment, should not delay the adoption of effective and proportionate measures aimed at preventing a risk of serious damage. And irreversible to the environment at an economically acceptable cost".

The principle of preventionwhich according to Professor Maurice KAMTO is a principle which implies another which is that of precaution. If it can be confused with the precautionary principle, it is nevertheless an outgrowth which emphasizes the need to refrain from acts harmful to the environment and human health. It is even a corollary of the principle of sovereignty over natural resources which impose on the State the obligation to prevent cross-border pollution.

The polluter pays principle is a principle according to which the costs resulting from the prevention, reduction of pollution and the fight against it and the restoration of polluted sites, must be borne by polluters.

The principle of responsibility, which places on the person whose action, is the source of conditions liable to degrade the environment or harm human health, the obligation to eliminate or have these conditions eliminated. This will concern the obligation for the producer of hazardous waste to eliminate or have this waste disposed of. This principle is a principle according to which any person who, by his action, creates conditions likely to be harmful to human health and the environment and who is required to ensure or cause to be ensured their elimination in the conditions to avoid such effects.

The Cameroonian legislator recognizes both the civil and criminal liability regime. This is the reason why Professor Michel PRIEUR thinks that the producer or holder of the waste remains responsible for their elimination whatever its effect on the environment, forcing them to bear the damaging affects does not bring any harm. Innovation in relation to the foundations of civil liability. In Cameroon, is civilly liable, without the need to prove fault, any person who, (...) caused bodily injury or material damage... As such, there is both a tort liability and another contractual.

The principle of participation, which generally calls for the association of all social actors in the preservation of the environment and particularly in the management of waste, including hazardous waste. Multidimensional, the principle first involves the association of citizens, sectors of activity and other groups and public or private entities concerned in the development of policies. It then involves informing and raising the awareness of actors on direct or indirect threats to the environment and the means to remedy them. Finally, it implies their contribution to environmental actions and their compliance with environmental requirements.

\subsection{Operational Principles Arising from the Basel and Bamako Conventions}

The Basel and Bamako [10] Conventions have principles closely linked to the environmentally sound management of waste and the regulation of its management.

First, speaking of the principles closely linked to the concept of environmentally sound management of waste, arising from the conventions to which Cameroon is a party integral. These are the principles for the production and transport of waste and those common to all stages.

First, the principles relating to the generation and transport of waste have been clearly addressed by these two legal instruments. Indeed, according to the preamble of the Basel Convention, there is no doubt that: "the most effective way to protect human health and the environment from the dangers posed by waste consists in reducing its production at minimum from the point of view of quality and / or potential danger. Reinforcing this evidence, Article 4, paragraph 2 alien urged States to «ensure the production of hazardous wastes and other within the country is reduced to a minimum, taking into account social, technical and economic considerations".

This provision does not require the adoption of particular methods but the introduction of technological innovations or legal changes, in order to achieve the objective of reducing waste generation. Furthermore, one of the objectives of the Basel and Bamako conventions is the reduction of transboundary and internal movements of waste. The preamble to its conventions states that this is an obligation to reduce the movement of waste. Thus, the parties take measures to: "Ensure that the transboundary movements of hazardous wastes and other wastes are reduced to a minimum compatible with an efficient and environmentally sound management of such wastes and that they are carried out in a manner that protect human health and the environment against the harmful effects which could result ".

Like the Clemenceau affair, which brought this issue up to date because France wanted to dismantle its aircraft carrier in India, which environmental NGOs have strongly decried? Seized of the question, the French Council of State and the Indian Supreme Court will rule unfavourably, based on the fact that in particular because it contains asbestos, extremely harmful substance, this building was comparable to toxic waste which should not be exported to India, especially since its dismantling was potentially dangerous for the environment.

If this case marks an open violation of the Basel Convention by the French state, many other attempts to transfer obsolete boats to countries in the South take much more subtle and difficult to detect routes. The ban on the 
export of ships containing dangerous substances to developing countries for dismantling (cf. infra "Decision VII / 6 of COP7") is often bypassed: either by selling a ship to a private individual who, once owner, will have complete freedom to have the boat demolished on the spot; or by claiming the reuse of the ship in other forms, as evidenced by the case of the ship SS Blue Lady (alias SS Norway, SS France).

In addition, it is also worth highlighting the case of the Probo koala on the dumping of toxic waste from Abidjan violating the provisions of the Basel Convention on the control of trans boundary movements of hazardous waste, violating on the one hand, the European community law which lays down a fundamental principle: that of polluter pays and on the other hand, the provisions of the Commission on Human Rights, which condemns the dumping of toxic and harmful waste in developing countries. As such, it is clear that any country should ensure that the disposal of waste produced on its territory is done by means compatible with environmentally sound management, recognizing that it can be both profitable and environmentally friendly rational to treat certain waste outside the national territory. Then, the principles common to all stages complete this architecture. They relate to the principles of integrated production control against pollution and the principle of the integrated life cycle.

The principle of integrated pollution control which invites here to include the management of waste and especially hazardous waste in a strategy that takes into account the effects that they could have in association with other elements or in contact with the ambient environment, " it (principle of integrated control) aims to achieve a maximum degree of environmental protection through a multidimensional approach to pollution, without moving the source of pollution to another environment".

The principle of the integrated life cycle which must lead not only to consider the environmental impact of the single waste, but to take account of this impact from the extraction of the initial raw material to the production of waste, including the manufacture of product from which it is derived.

Second, the principle of regulating waste management has two components, namely the strict ban and the flexible ban.

In the first part, the principle of strict prohibition is considered as a new principle of environmental law and has been adapted following the illegal traffic in waste observed between States. It must be noted that the Basel Convention makes this principle the cornerstone of illegal traffic in waste, by stating that any illegal transboundary movement of waste is strictly prohibited.

Regarding the Bamako conventionin relation to this principle, it is already positioned by its title entitled: "the Bamako convention on the prohibition of importing hazardous waste into Africa and on the control of transboundary movements and the management of hazardous waste produced in Africa. «This title of the Bamako convention consolidates the principle of strict prohibition of cross-border movements of waste. Even if it is worth mentioning that the convention of formal prohibition of the transport of hazardous waste to Africa is less and less enforced these days.

In the second part, the principle of flexible prohibition, this principle has two variants, namely: control and authorization measures. Speaking of internal control measures for this principle, the framework law affirms that with regard to classified establishments, they must be subject to control measures in order to guarantee the individual the right to a healthy environment. In addition, the removal of waste must be subject to control and authorization measures.

Then, the Basel Convention by its title requires that the transport of waste from one place to another can be done in accordance with the regulations in force for this purpose. Finally, the Bamako convention on this subject only admits the transfer of waste between the States Parties, thus confirming their attachment to the control measure. Speaking of the authorization measure, it is the linchpin of waste management in Cameroon because all initiatives in waste management must be subject to the authorization procedure.

Clearly, the Cameroonian legislator affirms that: "are formally prohibited in view of Cameroon's international commitments, the introduction, the discharge, the storage or transit on national territory of waste produced outside Cameroon". Even if it is noted that Cameroon receives on its soil waste from other states, whether African or Western.

\section{International, Regional and Community Conventions That Have Been Ratified by Cameroon}

To clarify Cameroonian waste law within the general framework of international environmental law, it is necessary to examine in turn the sustainability of universal international instruments (1) and then we will focus on regional and community instruments (2).

\subsection{Universal International Instruments}

During the second half of the 20th century, several nations of the world came together on various occasions to make commitments in order to combat the negative impacts of human activities on natural ecosystems. Among the topics discussed, the constant increase in waste generated, as well as the resulting impacts, and there is no need to mention that they represent a major issue in the problem of waste management not only at the national level but also at the national level. At the World level, this is the reason why draw up a summary report of the main international meetings which aimed to provide solutions for the environmental problems of the planet, and which have taken place since the United Nations Conference on the Environment of 1972 and ratified by the Cameroon.

The Basel conventions, the Rio de Janeiro declaration, etc. will be discussed in turn.

The Basel Convention and its Protocol, Confronted in the 
1980s with the unprecedented development of transboundary movements of waste, their often harmful consequences and the unavailability in many national laws of effective rules. The international community has seized on the urgent need for a universal response to limit the transboundary movement of this waste. This reaction will take the form of a treaty, which will be adopted under the aegis of the United Nations Environment Program (UNEP) on March 22, 1989. It is the Convention on the control of transboundary movements of hazardous wastes and their disposal, more commonly referred to as the Basel Convention. It entered into force on May 5, 1992. The Convention thus posed itself as a "global agreement concluded with the aim of tackling the problems and challenges posed by hazardous wastes".

The Rio Declaration [11] which was the resolutions of the first United Nations Conference on the Human Environment, held in 1972, to which 113 delegates and two heads of state (Olaf Palme, from Sweden, and Indira Gandhi, from the India) took part, held in Stockholm, Sweden. This conference sensitized an entire generation to an issue that had not been discussed much until then, namely the planetary environment. It ensured the environment a permanent place in the global action plan and led to the creation of the United Nations Environment Program (UNEP). The conference and its aftermath revealed the international nature of the environment and introduced the idea of a relationship between development and the environment. It has been said that the only way to unite the countries of the world would be to give them a common enemy; this is what could become of environmental degradation.

In the wake of the Rio de Janeiro summit in 1992, Cameroon embarked on a process aimed at defining a comprehensive policy in the field of the environment. In fact, it was this Rio conference that made it possible to identify the challenges posed by waste to the whole world through its three chapters of Agenda 21, by devoting to chapter 20: An environmentally sound management of hazardous wastes, in chapter 21: The environmentally sound management of solid waste and wastewater issues and in chapter 22: The safe and environmentally friendly management of radioactive waste.

The Stockholm Declaration [12] which was the resolutions of the United Nations Conference on the Environment, which met in Stockholm from June 5 to 16, 1972 and considered the need for a common understanding and common principles which will inspire and guide the efforts of the peoples of the world to preserve and improve the environment. It aims to control, reduce or eliminate the release or leakage of persistent organic pollutants.

The Rotterdam Convention [13], which aims to encourage the sharing of responsibilities and cooperation between the parties in the field of international trade in certain dangerous chemicals with the aim of protecting human health and the environment against possible damage. It also contributes to the environmentally sound use of these hazardous chemicals by facilitating the exchange of information on their characteristics, using a national decision-making process applicable to their import and export, and ensuring communication of parts.

The Kyoto Convention [14] aims to reduce greenhouse gas emissions which are at the origin of climate change and the various other consequences (disasters, floods, etc.) which result from it.

The Vienna Convention [15] for the Protection of the Ozone Layer, adopted on March 22, 1985, recognizes the need for increased international cooperation in order to limit the risks that human activities could pose to the ozone layer.

The Montreal Conventionon Substances that Deplete the Ozone Layer takes its source in 1985 from the Vienna Convention which established mechanisms for international cooperation in the framework of research on the ozone layer and its effects. ODC substances (ozone-depleting-chemicals).

The MARPOL Convention (Marine Pollution) is the name of an international convention concerning pollution of the sea, drawn up within the framework of the International Maritime Organization (IMO).

Overall, Cameroon's participation in international conventions in the field of environmental protection and waste management is not negligible despite its selective nature.

\subsection{Regional and Community Legal Instruments}

Following the scandals of 1986-1987, relating to toxic waste dumping in African countries and the dramatic consequences on the health and environment of populations, African Governments, under the banner of the African Union, unilaterally condemn this trade by qualifying it as a "crime against Africa and the African populations". Despite the efforts undertaken by the OAU to fight against this traffic in the dumping of hazardous waste from developed countries to developing countries, it is clear that this practice continues to prevail in countries with low economic power in new forms. Namely: fraudulent "recycling" programs, the relocation of polluting industries, the "ecomafia»...

However, these movements and transfers of hazardous waste cause serious violations of fundamental human rights, such as the violation of the right to life and the right to health (to name but a few), without however this aspect being explicitly mentioned in any of the ratified conventions on this subject. Faced with the gravity and scope of the phenomenon, the former Commission on Human Rights took up the problem and adopted on 8 March 1995 resolution 1995/814 establishing a mandate of Special Rapporteur on "the harmful consequences of illicit movement and dumping of toxic and harmful products and wastes for the enjoyment of human rights".

With regard to international traffic between the countries of the North and the South, Western public opinion is scandalized and African Governments, under the auspices of the Organization of African Unity (OAU), have mobilized to put an end to these criminal practices. The Council of Ministers of the OAU, by its resolution 1153 (XLVIII) adopted on May 23, 1988, "declared that the dumping of nuclear and industrial wastes in Africa is a crime against Africa and the African populations" (art. 1). Reactions, going 
beyond the provisions provided for by the Basel Convention, considered being an international rule, it is important to see what the regional and community rules have.

First, speaking of regional rules, the Bamako Convention and the Maputo Convention will constitute the bulk of the regional rules. Their contribution is indisputable in the construction of African international environmental law and in general and in the harmonization of waste management in particular.

Regarding the Bamako Convention, it was adopted on January 30, 1991 by the conference of environment ministers of 51 African states on the ban on importing hazardous waste into Africa and on the control of transboundary movements and the management of hazardous waste produced in Africa. It was a reaction of African countries to the Basel Convention; it aims to make Africa a sanctuary, that is to say a geographic space free from foreign waste. Particularly interested and strongly mobilized during the conference which will see the adoption of the Basel Convention, the developing States in general and the African States in particular, come out somewhat disillusioned.

Unlike the Basel Convention, the Bamako text sets out a total ban on the import of hazardous waste into Africa from non-African states.

Ultimately, the Bamako Convention formally prohibits the importation into Africa of hazardous waste of foreign origin. This prohibition appears clearly in Article 4 (1) of the said convention which provides that: "all parties shall take appropriate legal, administrative and other measures in the territories under their jurisdiction in order to prohibit importation into Africa all hazardous wastes, for whatever reason, from non-contracting parties. Their importation is declared illegal under criminal sanctions".

This article confirms the purely regional character of the Bamako convention. It can be noted that the convention does not prohibit the transfer of hazardous wastes between African countries themselves. This room for maneuverer left to African countries appears.

At the same time as this initiative, a United Nations Environment Program (UNEP) working group, bringing together the main countries concerned, is set up to establish international regulations on the control of toxic waste as a gap in that waste, whether produced in Africa or outside Africa, is nonetheless dangerous.

Regarding the Maputo Convention, it is seen as a platform for the harmonization of environmental law in Africa. Therefore, it should be mentioned that three factors militate in favour of the hypothesis of a harmonization of environmental law by the Maputo Convention. The first factor is the extension of the normative field of the convention, compared to the initial text of Algiers. The second is the dynamic of capitalization of the main principles of international environmental law resulting from the Stockholm and Rio conferences, and finally the consecration of procedural rights, and consequently of the possible litigation of environmental law.

Then, the Algiers Convention of 1968 will come after a long transition marked by some legal initiatives aimed at reviving the regulations relating to natural resources. This convention appears as a legal instrument which innovates by its global character that underlines the Professor Alexandre KISS when he writes that: "its main characteristic is to concretize a global approach of the environment" [16]. It is also important to mention that this convention narrowly precedes an important stage in the formation of international environmental law, initiated by the Stockholm conference of 1972 .

The convention signed in Maputo on July 11, 2003 is the culmination of this long process. This is clearly the revision, albeit profound, of the initial text of 1968 and not the drafting of a new convention. It now has 43 articles compared to 25 originally, the latter having themselves been profoundly modified and supplemented.

This convention was largely inspired by recent regional and global environmental conventions. The resulting normative edifice, writes A. M. MEKOUAR, "necessarily bears the mark of these different borrowings, both in substance and in form. So much so that despite successful efforts at substantial harmonization and standardization editorial, there remains in spite of everything an almost irreducible part of heterogeneity, which is due to the multiplicity and the disparity of the normative sources having fed the text of Maputo".

Through this convention, African environmental law will ultimately have benefited from the advances made by international environmental law over the past two decades.

Second, speaking of rules with a community vocation, it will be highlighted the ACP / EU conventions, the legal instruments relating to CEMAC and the European Union.

First, the ACP / EU conventions are those which concern the environment in general. They are also interested in waste issues. These conventions have an important contribution to the consolidation of the regulatory framework for waste management in Cameroon through the various conventions that punctuate EU / ACP cooperation, like those of Lomé I to $\mathrm{IV}$ and the agreement of Cotonou on the impact of the environmental policy of cooperation in the ACP States.

However, the vulnerability of some ACP countries caused by the worsening problems of desertification, and institutional development as well as capacity building are elements that the cooperation intends to take into account. It should therefore be noted that the Cotonou agreement briefly evokes issues related to the environment because there is no reference to the environmental policies developed in the last two Lomé conventions. The Cotonou Agreement does not confirm these policies already in place. However, nothing justifies.

Second, the legal instruments of the Economic and Monetary Community of Central Africa (CEMAC) are taken within the great continental unit which is the African Union. This sub-regional organization is not primarily intended to protect the environment, its objectives being essentially economic and political. But with the ecological diplomacy reinforced in Africa by the preparation of the Earth Summit in Rio in 1992, the protection of the environment was invited in a more visible and increased way in the political agenda of 
the African authorities. The environmental dimension is present in the financing conditions of development projects, financial institutions and donors.

Third, the legal instruments of the European Union are based on general texts, most of which can be found in international law. In the specific case of waste management, the European Union ratified the Basel Convention from the first environmental programs because it was concerned with waste management. As such, it adopted a framework directive, namely that $\mathrm{n}^{\circ} 75-442$ of July 15,1975 relating to waste, amended by directive $n^{\circ}$ 91/156 of March 18, 1991, while adopting specific texts for certain wastes, such as hazardous waste. With directive $n^{\circ}$ 91/689 of 12 December 1991 relating to hazardous waste from the Official Journal of the European Community (OJEC) of 31 December 1991.

\section{Discussion}

Uncertainty about the rank of the international standard arises with the constitutional law of 1961 which removed the provision stating the superiority of treaties over Cameroonian national laws. This law only determines the competent bodies in matters of negotiation and ratification of conventions in its article 12 paragraph 4 . The Constitution of June 2, 1972 will follow the same logic while ignoring the option retained in Cameroonian law as for the place international conventions in the Cameroonian legal order.

According to Professor Adolphe MINKOA, it is not appropriate to give "excessive importance to the insertion of a specific provision stating the superiority of the international standard over the national standard". Antonio CASSESSE presumes a "de facto primacy of international law" [17]. The place of international conventions will however be affirmed with the constitutional law of January 18, 1996, which takes up more or less the wording of article 40 of the 1960 Constitution and enshrines the monist option with the rule of law. International law on domestic law.

The constituent will even take the opportunity to grant special status to international legal instruments relating to human rights. Indeed, it integrates the latter into theconstitutionality block. Now in Cameroonian law, all questions concerning the life of a human rights treaty are of a constitutional nature [18]. Ratifying a treaty on fundamental rights is, in reality, adding a catalog of additional rights to the Constitution, to paraphrase Professor Alain Didier OLINGA. Conversely, each denunciation of a convention of this type amounts to amputating the block of constitutionality from one of its elements, so that Professor Adolphe MINKOA asks himself whether the principle of constitutional rigidity should not reduce the room for maneuver in this regard.

From the introduction of international legal standards relating to fundamental rights to the Cameroonian constitutionality bloc, there are multiple consequences. These legal instruments are not subject to the reciprocity clause of article 45 of the law of 1996 because of this integration into the bloc and also because "ratification constitutes, in itself, a ticket for direct accession to the constitutional dignity «writes
Professor Alain Didier OLINGA. In addition, in Cameroonian law, they are no longer conventional standards, but constitutional standards. In doing so, the judge is responsible for granting them the protection due to any standard of this rank.

It seems opportune in the context of this article to question the impact of international environmental law on Cameroonian waste law, knowing that the framework International law on domestic law.

The constituent will even take the opportunity to grant special status to international legal instruments relating to human rights. Indeed, it integrates the latter into the constitutionality block. Now in Cameroonian law, all questions concerning the life of a human rights treaty are of a constitutional nature. Ratifying a treaty on fundamental rights is, in reality, adding a catalog of additional rights to the Constitution, to paraphrase Professor Alain Didier OLINGA. Conversely, each denunciation of a convention of this type amounts to amputating the block of constitutionality from one of its elements, so that Professor Adolphe MINKOA asks himself whether the principle of constitutional rigidity should not reduce the room for maneuver in this regard.

From the introduction of international legal standards relating to fundamental rights to the Cameroonian constitutionality bloc, there are multiple consequences. These legal instruments are not subject to the reciprocity clause of article 45 of the law of 1996 because of this integration into the bloc and also because "ratification constitutes, in itself, a ticket for direct accession to the constitutional dignity «writes Professor Alain Didier OLINGA. In addition, in Cameroonian law, they are no longer conventional standards, but constitutional standards. In doing so, the judge is responsible for granting them the protection due to any standard of this rank.

It seems opportune in the context of this article to question the impact of international environmental law on Cameroonian waste law, knowing that the framework.

Cameroon's general legal system is Kelsenien-type, that is, lower standards are subordinated to those of higher categories to be valid.

\section{Conclusion}

In a laconic way, the legal framework of waste in Cameroon by international law, we have been allowed to note that it is effective by the contribution of international rules in terms of management of waste having its source, of on the one hand, soft law rules such as resolutions, recommendations and declarations, and on the other hand, international conventions such as those before Stockholm and those from Stockholm to Rio de Janeiro and the rules having their source international protocols such as the Montreal and Kyoto protocols. As such, we are entitled to assert that the international waste management standards applicable in Cameroon allow, together with internal rules, a real framework for waste management. 


\section{Conflict of Interest Statement}

No potential conflicts of interest are disclosed.

\section{Acknowledgements}

I thank my colleagues in the Public Law Department, in particular Professors KAM YOGO and MOMO FOUMTHIM, for their support in writing this article, their openness and hospitality, and their willingness to answer seemingly endless questions often with documentation included. Special thanks to the people named in this article, to the teachers of the Faculty of Legal Sciences of the University of Douala, where I have always found hospitality, information and the opportunity to explore diverse perspectives in the field of the research.

\section{References}

[1] GNANGUI (A), Waste law in Africa, the case of Cote d'Ivoire, Harmattan, collection of African studies, 2010.

[2] On the meanings, origin, basis and distinction between ratification and signature, see. NGUYEN QUOC DINH et alii, Droit international public, 7th ed., Paris, L. G. D. J., 2002, 1510 p., P. 139 et sq.

[3] MINKOA SHE (A), Human rights and criminal law in Cameroon, Paris, Economica, Coll. "The Life of Law in Africa", 1999, $321 \mathrm{p}$

[4] KAMTO (M), Environmental Law in Africa, Paris, EDICEF, 1996, 416 pages.

[5] RAZ (J), legal principals and the limits of the law, yale LJ, 1972 , p 823, quoted by DE SADELEER (N), the principles of the polluter, of prevention and of precaution - essay on the genesis and the legal scope of some principles of environmental law, Bruylant, Brussels, 1999, p. 234.

[6] DWORKIN (R), Taking rights seriously, cambrige, Mass, Harvard Universty press, 1977, p 35 and "positivism", D, and S., $1985, \mathrm{n}^{\circ} 1$, p. 31 , cited by DE SADELEER $(\mathrm{N})$, the principles of the polluter, prevention and precaution - essay on the genesis and the legal scope of some principles of environmental law, Brussels, Bruylant, 1999, p. 233.

[7] DOUNIAN (A), the legal regime of waste management in Cameroon, doctoral thesis in public law, university of yaoundé 2 (soa), April 2009

[8] Bamako Convention on the prohibition of importing hazardous wastes into Africa and on the control of transboundary movements and management of hazardous wastes produced in Africa (1991).

[9] Law $\mathrm{n}^{\circ}$ 96/12 of August 5, 2004 on the framework law relating to environmental management.

[10] Rio de Janeiro Convention, on biodiversity, climate change, the fight against desertification in forests, in 1992.

[11] Bale Convention on the Control of Trans boundary Movements of Hazardous Wastes and Their Disposal (1989) and the Protocol on Liability for Compensation (1999).

[12] Stockholm Convention on Persistent Organic Pollutants (2001).

[13] Rotterdam Convention on the Prior Informed Consent Procedure for Certain Hazardous Chemicals and Pesticides in International Trade (1998).

[14] The Kyoto Protocol is an international agreement aimed at reducing greenhouse gas emissions and which comes in addition to the United Nations Framework Convention on Climate Change, whose participating countries have met once a year since 1995 .

[15] Vienna Convention for the Protection of the Ozone Layer (1985) and Protocol on Substances that Deplete the Ozone Layer (1987).

[16] KISS (A), International Environmental Law, Paris, Pedone, 2000, 487 pages.

[17] CASSESSE (A), Modern constitutions and international law ", R. C. A. D. I., 1985, vol. 192, p. 39.

[18] OLINGA (A. D), The development of rights and freedoms in the revised Cameroonian Constitution, Universal Review of Human Rights, 1996, vol. 8, n 4-7, pp. 116-126. 